\title{
Resistivity Measurements to Assess the Freeze - Thaw Attack on Concrete - Lab Specimen and Real Structure
}

\begin{abstract}
Frank Spörel
Federal Waterways Engineering and Research Institute (BAW), Kussmaulstraße 17, 76187 Karlsruhe, Germany, frank.spoerel@baw.de

Abstract. Waterway structures like locks are exposed to a severe freeze-thaw-attack. A sufficient resistance of concrete against this exposure has to be assured. In Germany the concrete for the exposure class XF3 of federal waterway structures has to be tested in the laboratory by the CIF-Test in addition to descriptive requirements. To establish this procedure experiences on concrete mix designs which have been applied in the past were considered as well as research concerning the transferability of laboratory tests to practical experience. One important aspect was a service life study on the degree of water saturation of the concrete under practical conditions in combination with the temperature exposure. The paper presents the results of freeze-thaw tests on lab specimens and cores of concrete elements stored differently and tested at different ages. For a better understanding of the processes of the freeze-thaw attack during the freeze-thaw tests monitoring data of resistivity has been analyzed and compared to hardened concrete properties. The water absorption inside the specimen during capillary suction and the freeze-thaw-cycles could be monitored at different distances to the surface. Correlations of the water absorption to the initiation and development of internal damage were observable. A consideration of the results of the freeze-thaw tests and the resistivity measurements enables a better evaluation of long-term resistivity monitoring data of a lock. It allows for an assessment of the transferability of results of the CIF-Test to practical experience.
\end{abstract}

Keywords: Freeze-Thaw Attack, Resistivity, Monitoring, Concrete Core, Lab Specimen.

\section{Introduction}

In Germany for hydraulic structures like locks or weirs there are special requirements concerning concrete properties. As they are massive structures a low heat of hydration of the concrete to reduce restrain is important and on the other hand a high durability for a service life of hundred years. Freeze-thaw resistance is a very important durability aspect for those structures as the high water saturation of the lock chamber walls between head and tail water results in a severe freeze-thaw attack. During the initial test of the concrete intended for parts of the structures in XF3 exposure a performance test is required for new structures under the responsibility of the Federal Ministry of Transport and Digital Infrastructure. The CIF-Test according to (BAW, 2012) has to be passed. The procedure is similar to the RILEM recomendation (Setzer et al., 2004).

Before the mandatory introduction of this test questions concerning the transferability of the results of laboratory tests to practical experience were intensively discussed. To address that question the monitoring of the temperature and moisture exposure of real structures was supposed to be an adequate way to get reliable information on this question. Different structures like bridges, tunnels and locks were equipped with sensors for long term monitoring campaigns. A detailed analysis of the freeze-thaw attack on concrete structures based on monitoring data of real structures is published in (Spörel, 2013). The main 
differences between XF1 and XF3 exposure have been worked out for an example of a lock. The monitoring of the lock has been continued for 16 years during the whole service life of the lock so far and can be evaluated. As the monitoring data gives an impression of the complete history of the freeze-thaw attack during the previous service life of the structure (Spörel, 2016) it can be considered in evaluating the surface scaling observed at the structure.

To support the evaluation of the long-term resistivity monitoring of the lock the paper describes resistivity monitoring results on the freeze-thaw attack during the CIF-Test on lab specimens and concrete cores which were equipped with the same sensors as the lock.

\section{Principles to Monitor the Freeze-Thaw Attack on Concrete}

\subsection{General}

Concerning freeze-thaw attack the temperature and the degree of saturation are decisive parameters. If a critical degree of saturation is reached a freeze-thaw damage can occur (Fagerlund, 1977). As a continuous direct measurement of the degree of saturation is not possible an indirect determination of the degree of saturation by means of resistivity measurements was chosen. A calibration is required to account for different influencing parameters on the resistivity (Elkey and Sellevold, 1995; Spörel, 2013).

\subsection{Monitoring System}

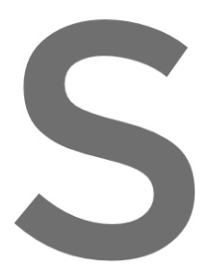

\section{The resistivity measure sensor consisting of sever insulating plastic ring bet concrete between two ad distance of 7 to $87 \mathrm{~mm}$
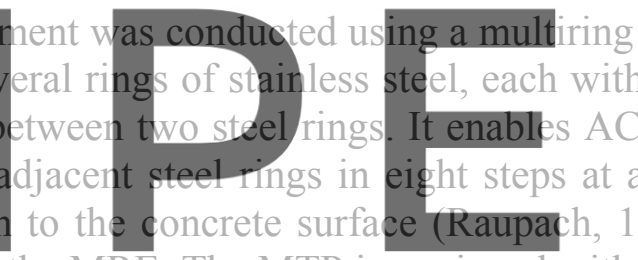
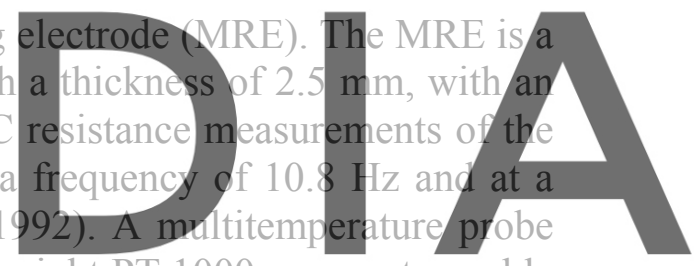

(MTP) is installed near the MRE. The MTP is equipped with eight PT 1000 sensors to enable arrangement of a measuring point is shown in Figure 1.
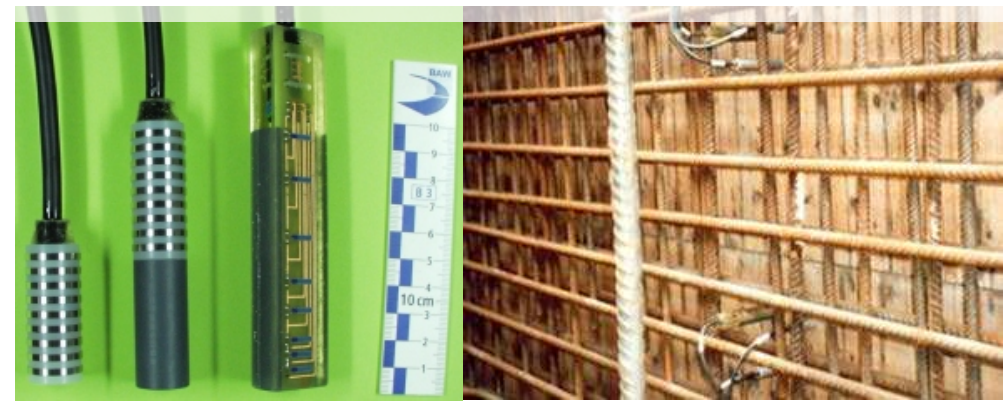

Figure 1. MRE and MTP (left), Sensor installation in a structure (right) (Spörel, 2019).

\subsection{Focus of Data Evaluation}

One aspect to evaluate the intensity of a freeze-thaw attack is the number of freeze-thaw cycles. As the freezing temperature of water in the pore structure of concrete depends on the pore size (Brun et al., 1977; Setzer, 2000) a simple evaluation of temperature data might be 
misleading concerning the intensity of a freeze-thaw attack. The freezing of water in the pore structure is decisive to activate the micro-ice-lens pump according to (Setzer, 2002). Resistivity measurements indicated that a minimum degree of saturation is required for the freezing of water in the pores (Spörel, 2013). In a hygroscopic saturation state only finer pores are filled with water and no freezing of water was observed at certain temperatures below 0 ${ }^{\circ} \mathrm{C}$. The approach of (Brun et al., 1977; Setzer, 2000) could be detected by resistivity measurements (Spörel, 2013; Spörel, 2016).

The effect of temperature on the resistivity has to be compensated to monitor concrete saturation. The investigations have shown that the Arrhenius approach (equation 1) is working well at concrete temperatures higher than $0{ }^{\circ} \mathrm{C}$ if the activation energy is determined and considered adequately (Spörel 2013, Spörel 2016). The constant b correlates to the degree of saturation of the concrete and has to be adapted at changing degrees of saturation.

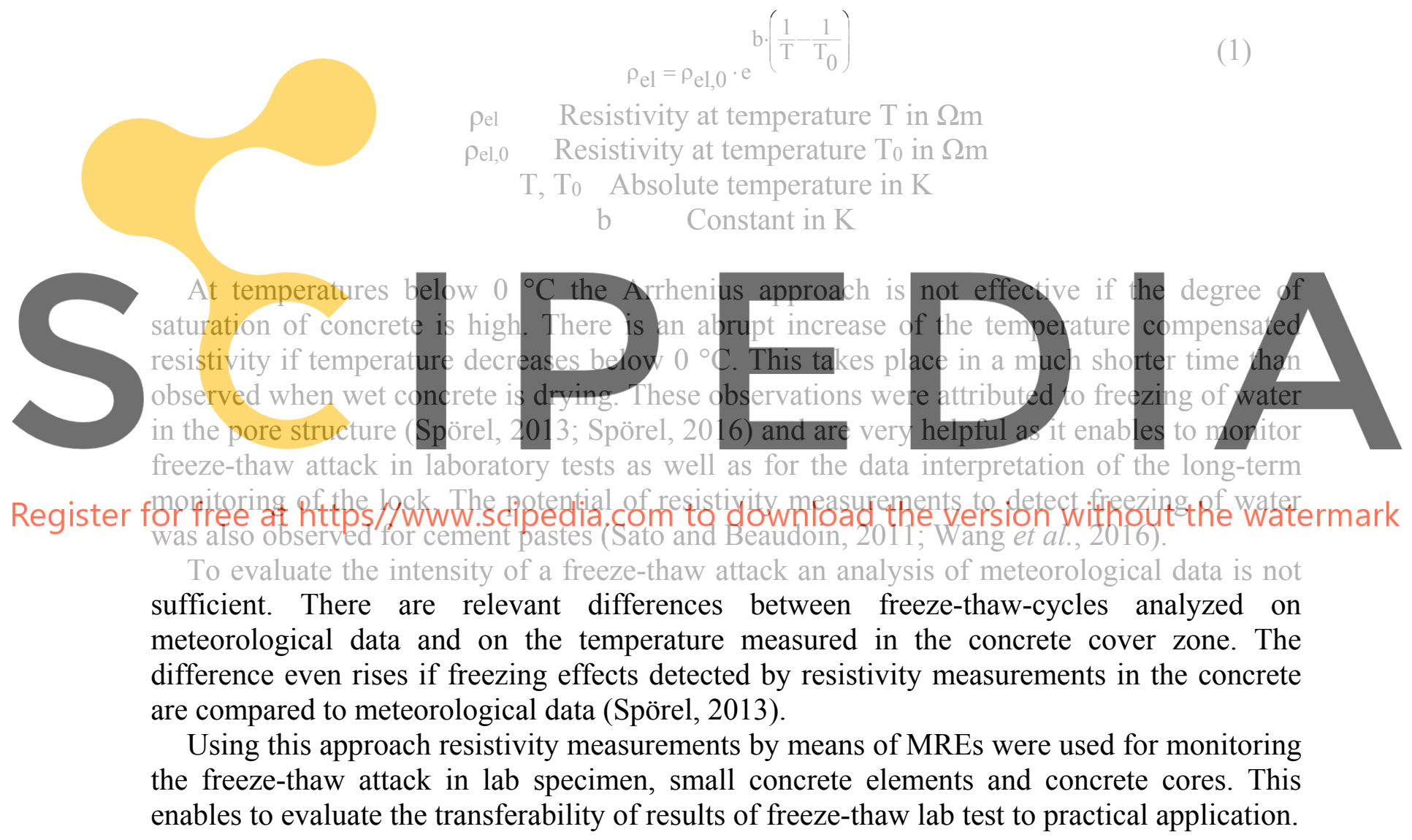

\section{Investigation Concept}

The transferability of results of freeze-thaw tests to practical experience has always been discussed concerning adequate testing ages and storage conditions of the lab specimens. The pore structure of the concrete is influenced by that and important as transport mechanisms play an important role. In (BAW, 2012) the storing conditions for the CIF- and CDF-test are described for different testing ages. As usually concrete with a slow strength development is used for hydraulic structures the standard testing age is $56 \mathrm{~d}$ after storage in water for $14 \mathrm{~d}$. 
To address this question investigations were realized on a concrete with the same composition and the same source of raw materials as used in the lock described in (Spörel, 2013; Spörel 2016). A concrete with $270 \mathrm{~kg} / \mathrm{m}^{3}$ CEM III/A $32.5 \mathrm{~N} \mathrm{LH}, 80 \mathrm{~kg} / \mathrm{m}^{3}$ fly ash, a water content of $143 \mathrm{~kg} / \mathrm{m}^{3}$ and an aggregate content of $1876 \mathrm{~kg} / \mathrm{m}^{3}$ was investigated.

A set of five lab specimen for the CIF-Test at different ages were cast as well as two concrete elements. The concrete elements and two additional lab specimens for each test series were equipped with MREs and MTPs to monitor the resistivity during the CIF-Test and the storage of the elements under natural exposure up to a distance to the surface of $42 \mathrm{~mm}$. The testing ages were set at $28 \mathrm{~d}, 56 \mathrm{~d}$ and $365 \mathrm{~d}$ for the lab specimens. At the testing age of $365 \mathrm{~d}$ two different storing conditions were applied (demoulding after $14 \mathrm{~d} ; 351 \mathrm{~d} 20^{\circ} \mathrm{C}, 85 \%$ rel. humidity; demoulding after $2 \mathrm{~d}$, water storage at $20^{\circ} \mathrm{C}$ for $321 \mathrm{~d}, 20^{\circ} \mathrm{C} / 65 \%$ rel. humidity for $42 \mathrm{~d}$ ). Additionally concrete cores were taken from the concrete element stored in the field. The cores were tested at an age of $56 \mathrm{~d}, 365 \mathrm{~d}$ and $6.5 \mathrm{a}$. As example results of the 6.5 years old cores are presented. The design of the element and the position of the cores and sensors are shown in Figure 2.
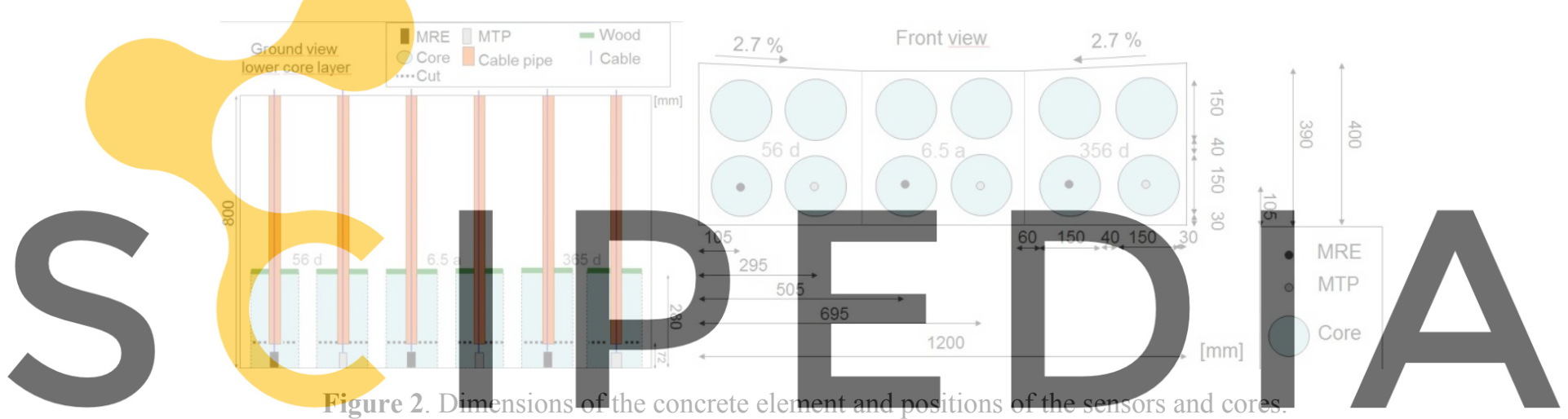

Register for frefactetetpsffywwkscipedia.com to download the version without the watermark

Additionally the strength development of the concrete was determined and summarized in Table 1 for cylindrical specimens with a height to diameter ratio of 2.0 for the lab and core specimens. The strength of the core specimens is lower than of the lab specimens. This confirms findings in the literature (The Concrete Society 2004; DIN EN 13791/A20 (2017).

The carbonation depth was determined on slabs 100x100x500 mm which were stored under the same conditions as the specimens for the CIF-Test and the concrete element. For slag cement concrete the carbonation depth might influence the scaling of concrete during the CIF-Test. Results are summarized in Table 1.

Table 1. Test Results for compressive strength and Carbonation.

\begin{tabular}{ccccccc}
\hline Concrete age & \multicolumn{2}{c}{$\mathrm{f}_{\mathrm{cm}}\left[\mathrm{N} / \mathrm{mm}^{2}\right]$} & \multicolumn{4}{c}{$\mathrm{d}_{\mathrm{c}}[\mathrm{mm}]$} \\
& Lab specimen & core & $20 / 65$ & $20 / 85$ & water & outdoor \\
\hline 56 & 37.3 & 31.8 & $\mathbf{1 . 8}$ & 1.0 & 0.0 & 2.7 \\
\hline 365 & 47.4 & 37.2 & 5.4 & $\mathbf{4 . 3}$ & $\mathbf{1 . 0}$ & 5.1 \\
\hline $6.5 \mathrm{a}$ & - & 33.3 & 13.0 & - & 8.0 & $\mathbf{8 . 0}$ \\
\hline
\end{tabular}

Results of the CIF-tests for selected storage and testing age versions according to section 3 
are presented in figures 3 and 4. Besides the standard testing age of $56 \mathrm{~d}$ two test series at an age of $365 \mathrm{~d}$ and results of cores at a high age of 6.5 years representing a situation at a structure at a higher age are compared as examples. The test results are evaluated concerning scaling and internal damage measured by the relative dynamic Young's modulus. The testing of cores of a structure in a freeze-thaw test includes effects of concrete casting, curing and exposure as well as influences of the coring process on the freeze-thaw resistance. This has to be kept in mind when comparing the results to those of standard lab specimens at a defined testing age and storing conditions.

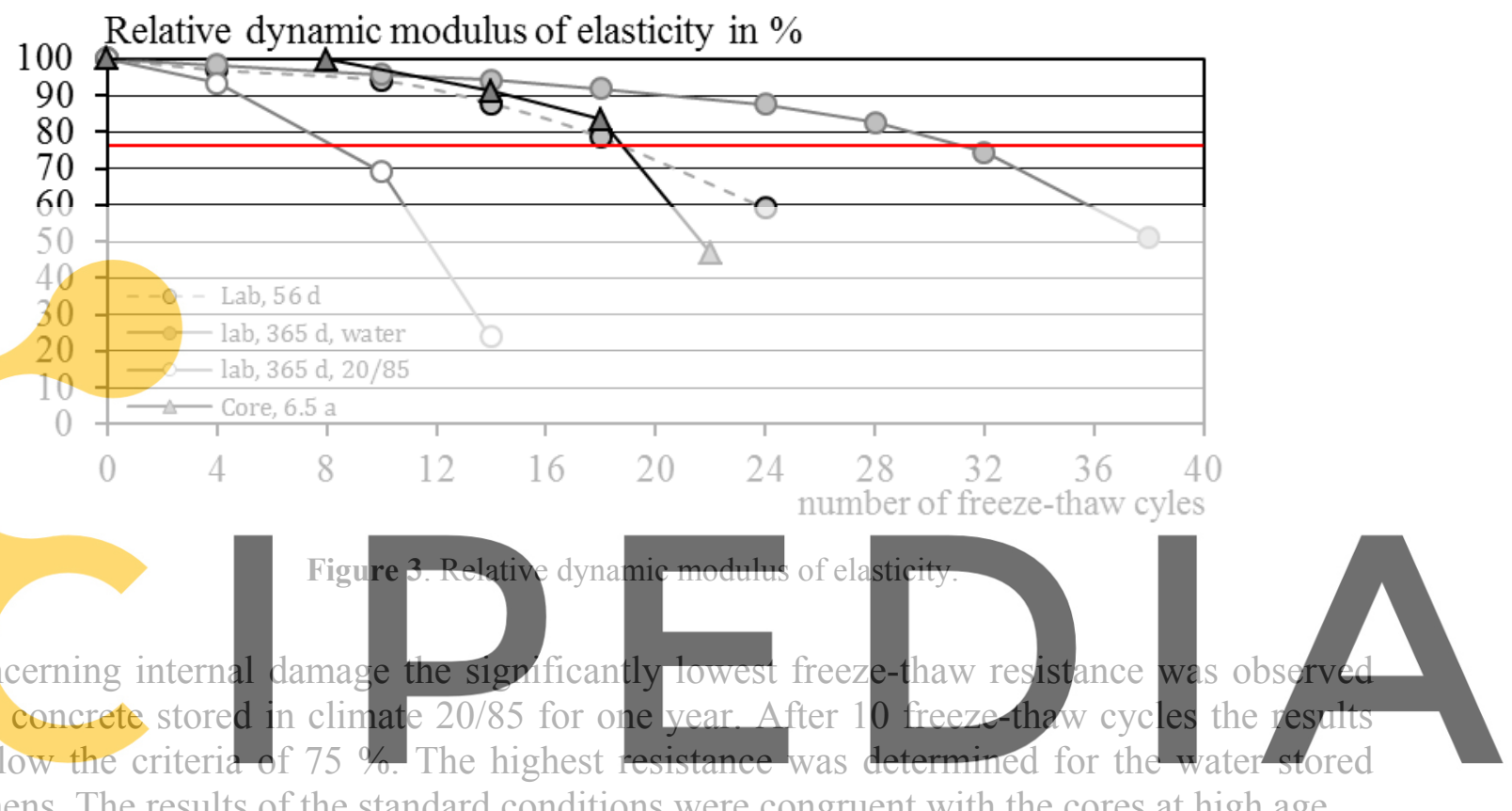

specimens. The results of the standard conditions were congruent with the cores at high age.

Register for free at https//www.scipedia.com to download the version without the watermark

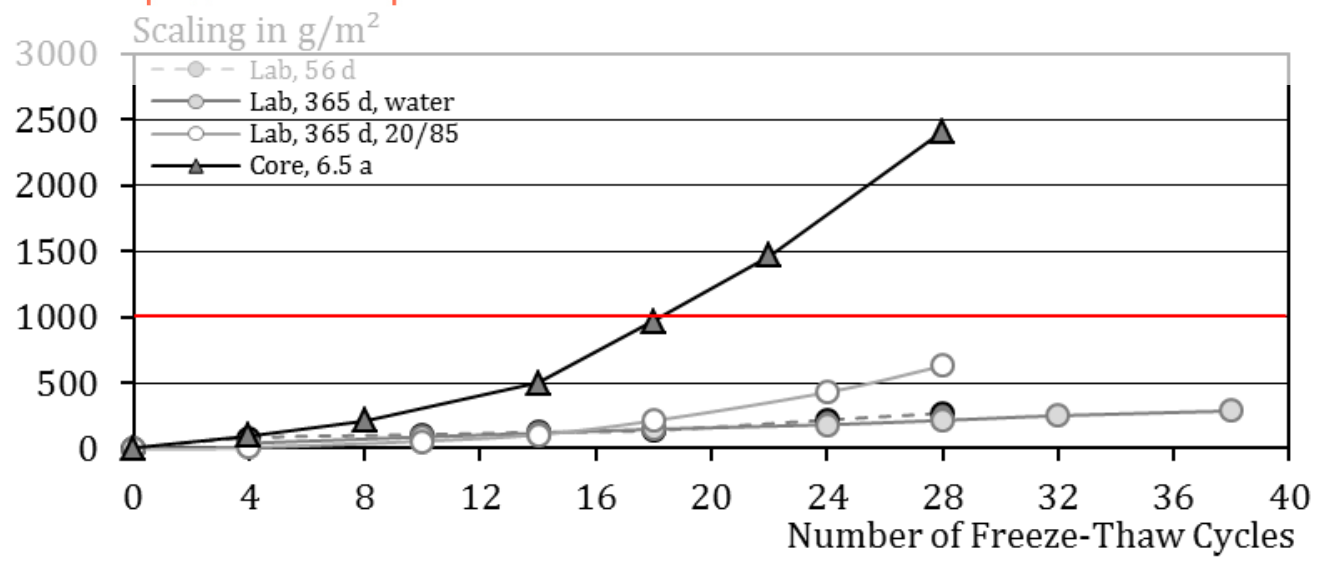

Figure 4. Scaling during the CIF-Test.

Looking at the lab specimens scaling was affected only slightly by the investigated storing conditions. The lab specimens tested at standard age and curing conditions showed 
comparable results to the water stored specimens tested at an age of $365 \mathrm{~d}$. The storage in climate $20^{\circ} \mathrm{C} / 85 \%$ rel. humidity resulted in the highest scaling for the lab specimens but still passed the criteria of $1000 \mathrm{~g} / \mathrm{mm}^{2}$ according to (BAW 2012). Considerably higher scaling was observed for the cores tested at an age of 6.5 years correlating to the carbonation depth.

Both for the scaling and the internal damage development the testing age is not the decisive parameter concerning the freeze-thaw resistance of the concrete. The effect of the curing regime on the internal damaged was very dominant for the lab specimens. The stronger impact of the storing conditions than the testing age was observed for the scaling as well. The scaling results of the cores yet showed a strong deviation of the lab specimens. Influences of the carbonation depth at the start of the CIF-Test might have an impact on the test results. A low carbonation for the standard and water storage, and higher values for the storage at $20{ }^{\circ} \mathrm{C}$ and $85 \%$ rel. humidity and for the cores were measured (Table 1, Bold type values).

\section{Resistivity Measurements}

For a better understanding of the processes during the CIF-Test the monitoring data was evaluated. An important parameter is the water absorption during the capillary suction phase and during the freeze-thaw cycles. As an example in Figure 5 results of the resistivity measurements in a distance of $32 \mathrm{~mm}$ to the surface and the weighing of the samples for the period of capillary suction before the start of the freeze-thaw-cycles are shown. The weighing data illustrate the great influence of the storage conditions of the specimens. By oven drying

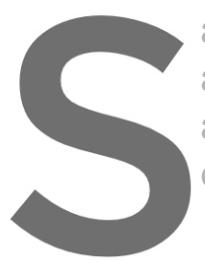
at $105^{\circ} \mathrm{C}$ the degree of saturation of the differen
and after capillary suction (Table 2 ). The degree
already high before the capillary suction starts
climate $20^{\circ} \mathrm{C} / 85 \%$ rel. humidity has a very muc Tam
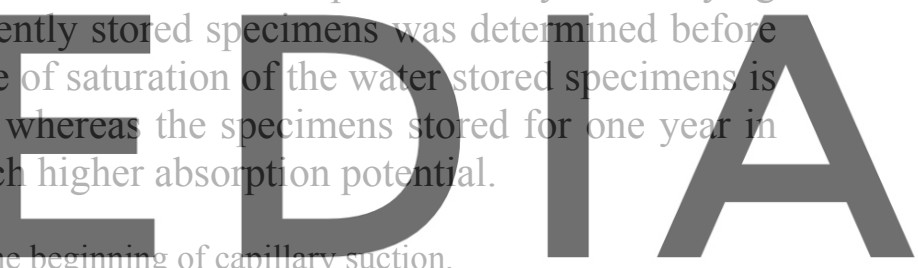

Register for free at https//www.scipedia.com to down/loring conditions

\begin{tabular}{ccccc} 
& $20 / 65$ & $20 / 85$ & water & outdoor \\
\hline $\begin{array}{c}\text { Degree of saturation before } \\
\text { capillary suction [\%] }\end{array}$ & 51 & 57 & 82 & 67 \\
\hline $\begin{array}{c}\text { Degree of saturation after } \\
\text { capillary suction [\%] }\end{array}$ & 63 & 79 & 90 & 78 \\
\hline
\end{tabular}

The resistivity data illustrate that in a measuring depth of $32 \mathrm{~mm}$ from the surface only for the concrete stored for one year in climate $20{ }^{\circ} \mathrm{C} / 85 \%$ rel. humidity a decrease in resistivity is observed during the capillary suction period. The decrease of resistivity is caused by a rising degree of water saturation in that measuring depth of $32 \mathrm{~mm}$. The resistivity of the other specimens was not affected by water absorption in that measuring depth. According to Table 2 the highest rise of the degree of saturation during the capillary suction phase was observed for the specimen stored in $20{ }^{\circ} \mathrm{C} / 85 \%$ rel. humidity. This indicates that it might be plausible that only this specimen showed a change in resistivity at that measuring depth. Closer to the surface also for the other specimens a decrease of resistivity was observed. 


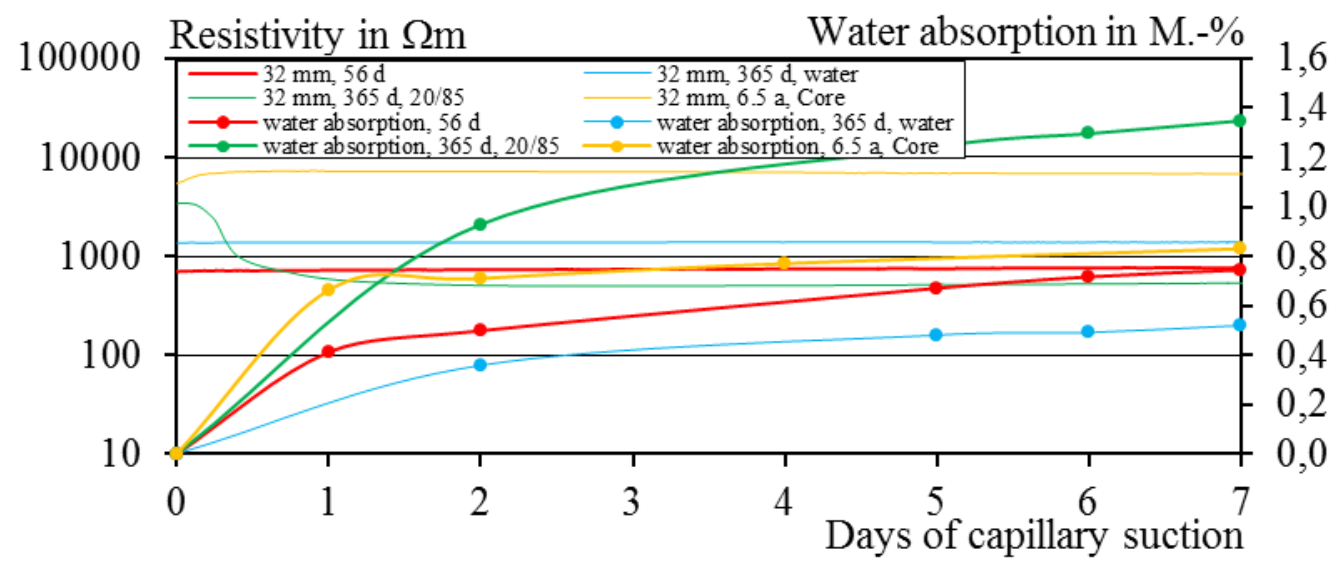

Figure 5. Water absorption during capillary suction.

Figure 6 shows the resistivity in a measuring depth of $42 \mathrm{~mm}$ during the freeze-thawcycles which was compensated for temperature effects according to equation (1) and the development of the relative dynamic modulus of elasticity. As described in (Spörel, 2013; Spörel, 2016) a typical increase and decrease of the resistivity is observed during the freezethaw cycles caused by freezing and melting of water in the pore structure. High resistivity is measured at concrete temperatures down to $-20^{\circ} \mathrm{C}$ when water in the pore structures is frozen

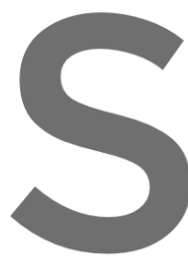
and low values are mea in a liquid state. The A water on the resistivity. Register for free a€https//www.scipedia.com to download the
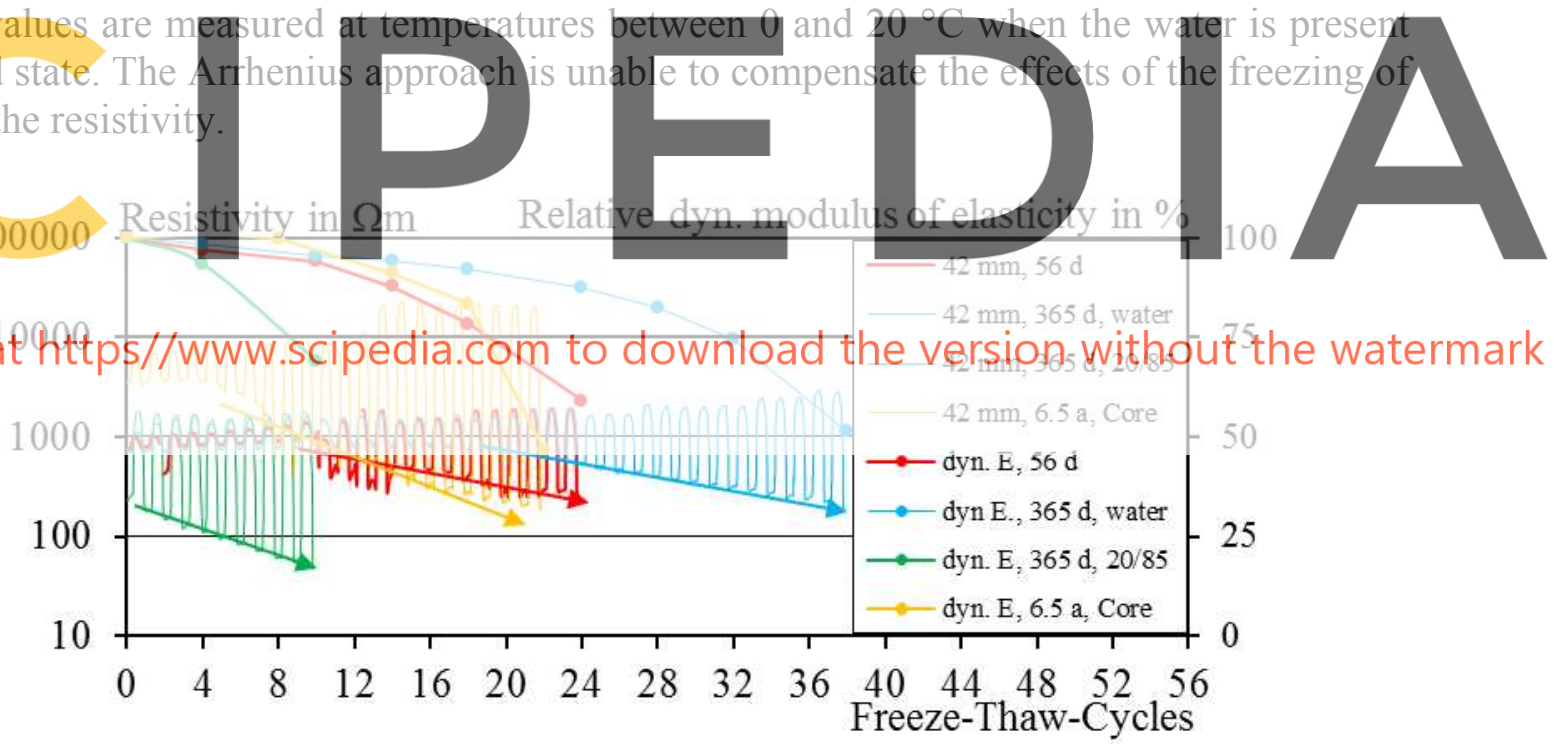

Figure 6. Temperature compensated resistivity and dynamic modulus of elasticity during the CIF-Test.

The low resistivity values decrease over time which is marked by arrows. This indicates the rise of the degree of saturation in that measuring depth. Analogue with that the dynamic modulus of elasticity starts to decrease. For the water stored concrete at an age of $365 \mathrm{~d}$ the decrease of resistivity starts at about 20 freeze-thaw cycles in that measuring depth. About at that time the relative modulus of elasticity also starts to decrease more rapidly as before. For the other samples similar correlations are observed. As proposed by (Fagerlund, 1977) the 
results seem to confirm that after reaching a critical degree of saturation the concrete is damaged. The water absorption according to the micro-ice-lens theory (Setzer, 2002) also seems to be confirmed. At certain distances to the surface no water transport was detectable during the capillary suction whereas during the freeze-thaw cycles a water transport occurred.

\section{Conclusions}

By means of monitoring the resistivity of concrete at different distances to the surface the micro-ice-lens theory (Setzer, 2002) and the theory of the critical degree of saturation (Fagerlund, 1977) seem to be comprehensible. The effect resulting from the freezing of water in the pore structure of concrete on the resistivity will be a helpful tool to further analyze the monitoring data of the lock concerning the frequency of such freezing incidents under practical conditions. The results of the resistivity monitoring in lab tests and the long-term monitoring of a lock in combination with a consideration of the surface damages at the lock enable to better evaluate the transferability of results of the CIF-Test to practical conditions.

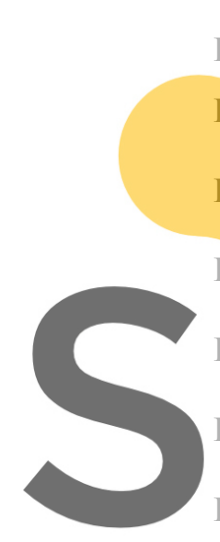

References

BAW Code of Practice (2012). Frost Resistance Tests for Concrete. Federal Waterways Engineering and Research institute (BAW), Karlsruhe, Germany

Brun, M., Lallemand, A., Quinson, J.-F. and Eyreaud, C. (1977). A new method for the simultaneous determination of the size and shape of pores: the thermoporometrie. Thermochemica Acta 21 (1),59-88

DIN EN 13791/A20 (2017). Assessment of in-situ compressive strength in structures and precast concrete components; Amendment A20, Beuth Verlag, Berlin.
lkey, W., Sellevold, E.J. (1995). Electrical resistivity of concrete, N
Publication No. 80
agerlund, G. (1977). The critical degree of saturation method of as
concrete. Materials and Structures 10, No. 58, 217-229.
aupach, M. (1992). Zur chloridinduzierten Makroelementkorrosion von GmbH. Schriftenreihe des DAfStb, Nr. 433 (in German), PhD thesis, RWTH Aachen University

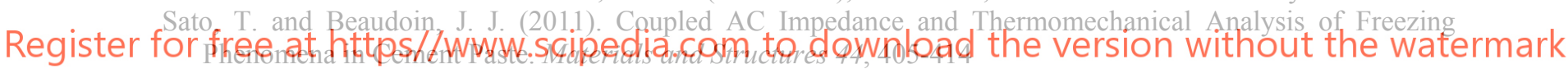

Setzer, M.J. (ed.) (2000). Micro Ice Lens Formation. 3rd Intrn. Bolomey Workshop - Pore solution in Hardened Cement Paste Essen 1998. Aedificatio, Freiburg, 89-112

Setzer, M. J. (2002). Development of the micro-ice-lens model. International RILEM Workshop on Frost Resistance of Concrete. RILEM Publications SARL, 133-145

Setzer, M.J. et al. (2004). RILEM TC 176-IDC: Internal damage of concrete due to frost action. Final recommendation: Test methods of frost resistance of concrete: CIF Test: Capillary suction, internal damage and freeze-thaw test - Reference method and alternative methods A and B. Materials and structures 37, 743 753

Spörel, F. (2013). Frostbeanspruchung und Feuchtehaushalt in Betonbauwerken. Berlin, Beuth Verlag GmbH. Schriftenreihe des DAfStb, Nr. 604 (in German), PhD thesis, RWTH Aachen University

Spörel, F. (2016). Freeze-Thaw-Attack on concrete structures -laboratory tests, monitoring, practical experience. Proceedings PRO 114 Conference on Materials, Systems and Structures in Civil Engineering - Frost Action in Concrete. Paris / RILEM Publications S.A.R.L., 151-160

Spörel, F. (2019). Monitoring of the freeze-thaw attack on concrete. The nordic concrete federation workshop proceedings No. 16 "Concrete in arctic conditions", 75-78

The Concrete Society (2004). In situ concrete strength. An investigation into the relationship between core strength and standard cube strength. Concrete Society Project Report No. 3, Camberley, UK.

Wang, Z., Wang, L., Yao, Y. (2016). Percolation in cementitious materials under freeze-thaw cycles investigated by means of electrical resistivity. Proceedings PRO 114 Conference on Materials, Systems and Structures in Civil Engineering - Frost Action in Concrete. Paris/RILEM Publications S.A.R.L., 201-210 